\title{
Early and late growth and blood pressure in adolescence
}

\author{
B L Horta, F C Barros, C G Victora, T J Cole
}

J Epidemiol Community Health 2003;57:226-230

See end of article for authors' affiliations

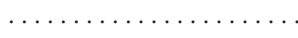

Correspondence to: Dr B L Horta, Rua Triunfo 3080, 96090-790

Pelotas, Brazil;

blhorta@phoenix.ucpel.tche.br

Accepted for publication 22 July 2002
Objective: To assess the effect of growth during infancy and childhood on blood pressure in adolescence.

Design: Birth cohort study.

Setting: Pelotas, southern Brazil.

Participants: 749 adolescents with complete information on birth weight and gestational age, as well as on anthropometric data at all three follow up visits (mean age 20 months, 42 months, and 15 years). Main outcome measurements: Systolic and diastolic blood pressure at adolescence.

Results: After controlling for possible confounding variables, birth weight was negatively associated with systolic blood pressure, one unit increase in standard deviation score of birth weight for gestational age was associated with a decrease of $1.23 \mathrm{~mm} \mathrm{Hg}(95 \%$ confidence intervals -2.03 to -0.43 ) in systolic blood pressure. Weight for age z score at the age of 15 years showed a strong positive association with systolic blood pressure, one unit increase in standard deviation score of birth weight for gestational age was associated with an increase of $4.4 \mathrm{~mm} \mathrm{Hg} 195 \%$ confidence intervals 3.50 to 5.3). Diastolic blood pressure was not associated with birth weight. For adequate for gestational age infants, the positive association between weight in adolescence and blood pressure became stronger when previous weights were added to the model.

br Conclusion: This study showed that early-as well as-late catch up growth is associated with increased systolic blood pressure in adolescence, whereas only late catch up is related with diastolic blood pressure. These findings suggest that catch up growth, irrespective of age, is associated with increased blood pressure in adolescence.
C atch up growth is defined as the phase of acceleration in growth that occurs after a period of growth retardation ends, favourable conditions are restored, and the children return to the original growth channel. ${ }^{1}$ In developed countries, most small for gestational age (SGA) infants catch up in growth during the first one or two years of life, with the greatest proportion of catch up occurring within the first six months of life, ${ }^{23}$ whereas, in developing countries, catch up among SGA infants is not as common. ${ }^{45}$ Catch up growth of SGA infants is widely regarded as beneficial for their health, as children with better nutritional status have lower morbidity ${ }^{6}$ and mortality. ${ }^{7}$ Also, by helping young girls overcome intrauterine growth restriction, the risk of low birth weight in the next generation may be reduced. ${ }^{89}$

It has been suggested that catch up growth might increase the risk of death from coronary heart disease. ${ }^{10}$ Eriksson $e t$ al ${ }^{11}$ and Forsen $e t$ al $^{12}$ followed up a cohort of infants who were born in the Helsinki University Central Hospital between 1924 and 1933 and who went to school in Helsinki. Eriksson et $a l^{11}$ reported that among men who had a low ponderal index (birth weight $(\mathrm{kg}) /$ birth length $(\mathrm{m})^{3}$ ) at birth an increase in body mass index from 3 years onwards was associated with increased risk of hospital admission or death from coronary heart disease, whereas among the men with a high ponderal index at birth an increase in body mass index during infancy was associated with reduced risk of coronary disease. Conversely, Forsen $e t$ al ${ }^{12}$ reported that among women, the highest risk of hospital admission or of death from coronary heart disease was observed among women who were short at birth but had caught up in height at 7 years, whereas catch up in weight did not increase the risk of coronary disease. Another Finnish study showed that subjects who were in a higher quartile of body mass index at age 7 than their birth weight quartile seemed to have an increased risk (odds ratio 2.3; $95 \%$ confidence intervals 0.9 to 5.4 ) of high blood pressure, dyslipidaemia or insulin resistance in adulthood. ${ }^{13}$
Leon et $a l^{14}$ with Swedish men reported a higher blood pressure among those men who were light at birth but whose adult height was above the median. However, studies of men born in Hertfordshire during 1911-30 have shown that infants with low birth weight and small weight gain during infancy had the highest prevalence of coronary heart disease, ${ }^{15}$ as well as raised levels of known cardiovascular risk factors such as: impaired glucose tolerance and diabetes ${ }^{16}$ and central obesity. ${ }^{17}$

In view of the conflicting evidence and the public health and clinical importance of elucidating the relation between catch up growth and morbidity, we decided to assess the effect of growth during infancy and childhood on blood pressure in adolescence in a cohort of adolescents aged 14-15 years, who have been followed up since birth in Pelotas, southern Brazil. In an earlier publication, we had showed in this cohort that SGA was associated with increased levels of blood pressure. ${ }^{18}$

\section{METHODS}

Pelotas has a population of about 350000 , where more than $99 \%$ of all births occur in a hospital. ${ }^{19}$ In 1982, the five maternity hospitals in the city were visited daily and all 5914 live births were included in the study. Mothers were weighed, measured, and interviewed during their hospital stay and their babies were weighed with calibrated paediatric scales. Gestational age was calculated according to the recalled date of the mother's last menstrual period. Children whose birth weight was below the 10th centile for gestational age and sex, according to the reference developed by Williams et al ${ }^{20}$ were classified as SGA.

In 1984 (mean age 20 months), a city wide census was conducted to locate children born in 1982, and $87 \%$ of the cohort was located. Children were weighed using a portable spring scale with an accuracy of \pm 100 g. A similar census was repeated in 1986 (mean age 42 months), when $84 \%$ of the children were located. 
Table 1 Characteristics of the original cohort and the cohort with complete data at birth and at all three follow up visits. Pelotas, Brazil, 1997

\begin{tabular}{|c|c|c|}
\hline Characteristics & Original cohort & $\begin{array}{l}\text { Cohort with complete data at birth and at all } \\
\text { three follow up visits }\end{array}$ \\
\hline \multicolumn{3}{|l|}{ Sex } \\
\hline Male & $3034(51.3)$ & $389(51.9)$ \\
\hline Female & 2879 (48.7) & $360(48.1)$ \\
\hline \multicolumn{3}{|c|}{ Family income (US\$) } \\
\hline 90 & 1288 (21.9) & $99(13.2)$ \\
\hline $91-270$ & $2789(47.4)$ & $364(48.7)$ \\
\hline $271-540$ & 1091 (18.5) & $178(23.8)$ \\
\hline $541-900$ & $382(6.5)$ & $53(7.1)$ \\
\hline$>900$ & $335(5.7)$ & $54(7.2)$ \\
\hline \multicolumn{3}{|c|}{ Maternal schooling (years of schooling) } \\
\hline 0 & 1961 (33.2) & $201(26.0)$ \\
\hline $1-5$ & 2454 (41.5) & $319(42.6)$ \\
\hline $6-9$ & $653(11.1)$ & $92(12.3)$ \\
\hline 10 & $839(14.2)$ & $136(18.2)$ \\
\hline \multicolumn{3}{|l|}{ Birth weight (g) } \\
\hline$<2500$ & $534(9.0)$ & $38(5.1)$ \\
\hline 2500 & 5375 (91.0) & 711 (94.9) \\
\hline \multicolumn{3}{|c|}{ Gestational age (weeks)* } \\
\hline$<37$ & $294(6.3)$ & $38(5.1)$ \\
\hline 37 & 4380 (93.7) & $711(94.9)$ \\
\hline \multicolumn{3}{|c|}{ Birth weight for gestational age* } \\
\hline$<10$ th centile & $723(15.2)$ & $101(13.5)$ \\
\hline$\geqslant 10$ th centile & $4022(84.8)$ & $648(86.5)$ \\
\hline \multicolumn{3}{|c|}{ Change in weight for age $z$ score between birth and mean age of 20 months $\dagger$} \\
\hline$<-0.67$ & $1113(28.2)$ & $204(27.2)$ \\
\hline-0.66 to 0.66 & $1707(43.2)$ & $317(42.3)$ \\
\hline$>0.67$ & $1133(28.7)$ & $228(30.4)$ \\
\hline Total & 5914 & 749 \\
\hline \multicolumn{3}{|c|}{$\begin{array}{l}\text { *The figures of gestational age and birth weight for gestational age centile do not add to the totals shown in } \\
\text { the last row because of missing information. tThe figures of weight gain do not add to the totals shown in th } \\
\text { last row, as some children were not followed up in 1984. Percentages are shown in parentheses. }\end{array}$} \\
\hline
\end{tabular}

At the beginning of 1997, a systematic sample of 65 from the 259 city census tracts was selected. In each tract, all households were visited and adolescents born in 1982 were interviewed and later linked to their birth cohort records. All adolescents were weighed, measured, and their blood pressure was measured twice, at the beginning and in the end of the interview, in the sitting position with a calibrated aneroid sphygmomanometer with appropriate cuff size. For diastolic pressure, phase V of Korotkoff sounds was used. The mean values of the two measures were used in the analyses. Interviewers were medical students trained for one week in interviewing techniques and anthropometric and blood pressure measurements.

Birth weight $\mathrm{z}$ scores were computed using the following formula: $\mathrm{z}=(\mathrm{x}-\mathrm{mean}) / \mathrm{SD}$, where $\mathrm{x}$ is the infant's birth weight and mean and SD are the mean and standard deviation for each gestational age and sex group in the reference population. As Williams et $\mathrm{al}^{20}$ did not provide the mean birth weight and standard deviation for each gestational age and sex group, the 50th centile was used as the mean birth weight, and the standard deviation was estimated by subtracting the 10th from the 50th centile and dividing by 1.28. Using the
NCHS growth reference, ${ }^{21} \mathrm{z}$ scores were also calculated for weight adjusted for age in the follow up visits. Changes in $\mathrm{z}$ score between birth and the follow up visits were calculated and were referred to as "weight gain" in the results section and tables.

Variables were considered as potential confounders if they were believed to be related both to the exposure (catch up growth in the first year of life) and the outcome (diastolic and systolic blood pressure) but not in the causal pathway. The following variables were considered:

- family income: total income earned by family members during the month before the interview;

- maternal education: years of schooling completed with success;

- maternal weight at the beginning of pregnancy: obtained either by collecting the information on the mother's weight in the first two months of pregnancy from the antenatal care records or by asking the mother about her weight before the pregnancy;

- maternal height: mothers were measured soon after admission to the maternity hospital;

\begin{tabular}{lllllll} 
Table 2 & Correlation matrix between the anthropometric variables ( $\mathrm{n}=749)$ \\
\hline & $\begin{array}{l}\text { Weight for age z } \\
\text { score (1984) }\end{array}$ & $\begin{array}{l}\text { Weight for age z } \\
\text { score (1986) }\end{array}$ & $\begin{array}{l}\text { Weight for age z } \\
\text { score (1997) }\end{array}$ & $\begin{array}{l}\text { Weight gain } \\
\text { (1982-84) }\end{array}$ & $\begin{array}{l}\text { Weight gain } \\
\text { (1984-86) }\end{array}$ & $\begin{array}{l}\text { Weight gain } \\
\text { (1986-97) }\end{array}$ \\
\hline Birth weight z score (1982) & 0.44 & 0.39 & 0.29 & -0.46 & -0.11 & -0.13 \\
Weight for age z score (1984) & & 0.84 & 0.51 & 0.59 & -0.33 & -0.40 \\
Weight for age z score (1986) & & & 0.62 & 0.47 & 0.25 & -0.47 \\
Weight for age z score (1997) & & & 0.25 & 0.16 & 0.40 \\
Weight gain (1982-84) & & & & -0.23 & -0.27 \\
Weight gain (1984-86) & & & & & -0.11 \\
\hline
\end{tabular}

All correlations were significant at the 0.001 level (two tailed). 
Table 3 Changes in systolic blood pressure $(\mathrm{mm} \mathrm{Hg}$ ) associated with a $1 \mathrm{z}$ score increase in birth weight and weight for age $z$ scores at the mean ages of 20 months (1984), 42 months (1986), and 15 years (1997)

\begin{tabular}{|c|c|c|c|c|}
\hline \multirow[b]{2}{*}{ Model } & \multirow[b]{2}{*}{ Multiple linear regression equation } & \multicolumn{3}{|c|}{ Regression coefficient for systolic blood pressure in 1997 (age 15 years) } \\
\hline & & All children & SGA & AGA \\
\hline 1 & Birthweight z score 1982 & $-0.08(-0.84$ to 0.68$)$ & $-4.04(-8.82$ to 0.75$)$ & $-0.16(-1.13$ to 0.81$)$ \\
\hline 2 & $\begin{array}{l}\text { Birthweight z score } 1982 \\
\text { Weight for age z score } 1984\end{array}$ & $\begin{array}{l}-0.76(-1.60 \text { to } 0.09) \\
1.39(0.62 \text { to } 2.16)\end{array}$ & $\begin{array}{l}-4.89(-9.68 \text { to }-0.09) \\
2.39(-0.01 \text { to } 4.79)\end{array}$ & $\begin{array}{l}-0.78(-1.83 \text { to } 0.26) \\
1.26(0.45 \text { to } 2.06)\end{array}$ \\
\hline 3 & $\begin{array}{l}\text { Birthweight } z \text { score } 1982 \\
\text { Weight for age z score } 1984 \\
\text { Weight for age z score } 1986\end{array}$ & $\begin{array}{l}-0.84(-1.67 \text { to }-0.01) \\
-0.94(-2.21 \text { to } 0.33) \\
2.89(1.62 \text { to } 4.16)\end{array}$ & $\begin{array}{l}-4.98(-9.75 \text { to }-0.22) \\
-0.13(-4.15 \text { to } 3.89) \\
3.14(-0.90 \text { to } 7.18)\end{array}$ & $\begin{array}{l}-0.88(-1.91 \text { to } 0.15) \\
-1.06(-2.39 \text { to } 0.29) \\
2.87(1.54 \text { to } 4.21)\end{array}$ \\
\hline 4 & $\begin{array}{l}\text { Birthweight } z \text { score } 1982 \\
\text { Weight fo age } z \text { score } 1984 \\
\text { Weight for age } z \text { score } 1986 \\
\text { Weight for age } z \text { score } 1997\end{array}$ & $\begin{array}{l}-1.10(-1.88 \text { to }-0.31) \\
-0.79(-1.98 \text { to } 0.40) \\
0.21 \quad(-1.09 \text { to } 1.51) \\
4.44 \text { (3.57 to } 5.31)\end{array}$ & $\begin{array}{l}-5.09(-9.76 \text { to }-0.41) \\
-0.06(-4.01 \text { to } 3.88) \\
1.25(-3.06 \text { to } 5.56) \\
3.08(0.31 \text { to } 5.85)\end{array}$ & $\begin{array}{l}-1.15(-2.11 \text { to }-0.18) \\
-0.89(-2.14 \text { to } 0.36) \\
0.09(-1.27 \text { to } 1.46) \\
4.61(3.70 \text { to } 5.53)\end{array}$ \\
\hline $5^{*}$ & $\begin{array}{l}\text { Birthweight z score } 1982 \\
\text { Weight fo age z score } 1984 \\
\text { Weight for age z score } 1986 \\
\text { Weight for age z score } 1997\end{array}$ & $\begin{array}{l}-1.23(-2.03 \text { to }-0.43) \\
-0.59(-1.82 \text { to } 0.64) \\
0.26 \quad(-1.07 \text { to } 1.58) \\
4.38 \text { (3.50 to } 5.26)\end{array}$ & $\begin{array}{l}-4.02(-9.17 \text { to } 1.13) \\
-0.49(-4.80 \text { to } 3.82) \\
1.86(-2.91 \text { to } 6.64) \\
2.67(-0.35 \text { to } 5.69)\end{array}$ & $\begin{array}{l}-1.21(-2.20 \text { to }-0.22) \\
-0.67(-1.96 \text { to } 0.62) \\
0.13(-1.27 \text { to } 1.52) \\
4.53(3.60 \text { to } 5.46)\end{array}$ \\
\hline \multicolumn{2}{|c|}{ Number of children } & 749 & 101 & 648 \\
\hline
\end{tabular}

- maternal age at delivery: measured in complete years;

- maternal smoking during pregnancy: any consumption of cigarettes during pregnancy;

- breast feeding duration: the age at which breast feeding stopped completely.

- gender

Blood pressure was analysed as a continuous outcome. To account for possible confounding variables, the effect of catch up for weight on blood pressure was assessed by multiple linear regression.

\section{RESULTS}

In all, 1076 adolescents were found within the 65 census tracts in 1997. In this study, analysis was restricted to those 749 adolescents with complete information on birth weight and gestational age, as well as on anthropometric data at all three follow up visits. The study sample presented a lower proportion of low income families, low birthweight and preterm infants than in the original cohort (table 1). About $29 \%$ of the infants showed fast growth for weight, whereas $28 \%$ had slow growth. Occurrence of fast growth (gain of $>0.67 \mathrm{z}$ score) in the first 20 months was about 2.5 times

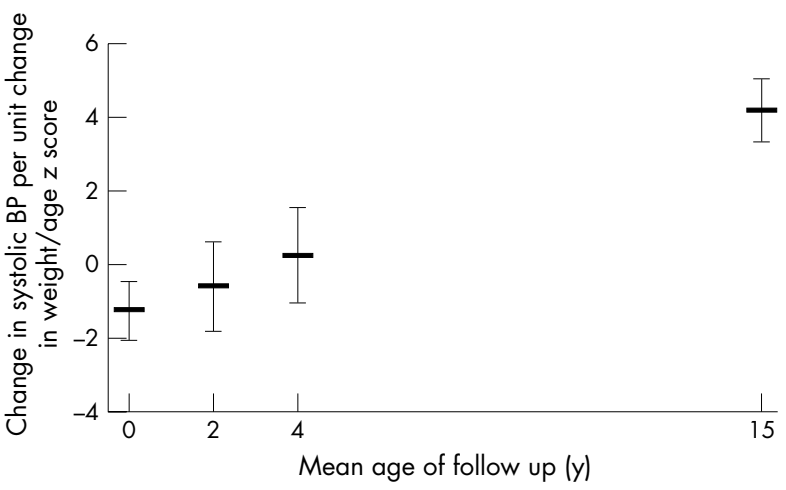

Figure 1 Changes in systolic blood pressure ( $\mathrm{mm} \mathrm{HG}$ ) associated with a $1 \mathrm{z}$ score increase in birth weight and weight for age $\mathrm{z}$ scores at the mean ages of 20 months, 42 month, and 15 years. Adjusted for: family income, duration of breast feeding, gender, maternal height, and maternal smoking during pregnancy. higher among SGA than adequate for gestational age (AGA) infants. Mean diastolic and systolic blood pressure were, respectively, 67.8 and $114.1 \mathrm{~mm} \mathrm{Hg}$

Table 2 shows the correlation coefficients of the anthropometric variables at birth and in the three follow up visits. Birth weight was associated positively with attained weight and negatively with weight gain. Weight measurements were positively correlated among themselves, as expected, the strongest correlations being among consecutive measurements. Weight gain measures were negatively associated with weight at the beginning of the period, and positively associated with weight at the end of the period.

Table 3 shows the multivariate analysis incorporating the anthropometric variables in a stepwise fashion. Birth weight showed an inverse association with systolic blood pressure when weight at 20 months was added to the regression model. Whenever a more recent weight was added, it became the more important predictor of blood pressure, with a direct association. The effect of previous weights became no longer significant, and often changed direction, after the inclusion of a later weight. When all four weights were included simultaneously (model 4), only birth weight and the last weight (at adolescence) remained significant for all children. There were

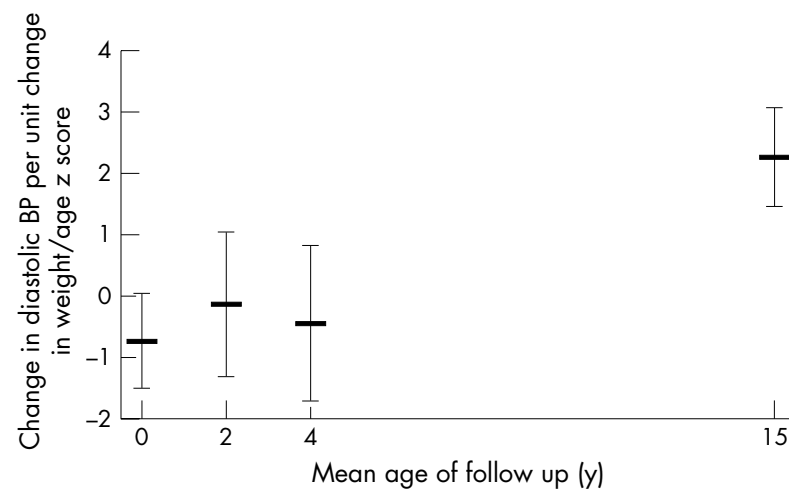

Figure 2 Changes in systolic blood pressure ( $\mathrm{mm} \mathrm{HG}$ ) associated with a $1 \mathrm{z}$ score increase in birth weight and weight for age $\mathrm{z}$ scores at the mean ages of 20 months, 42 month, and 15 years. Adjusted for: family income, duration of breast feeding, gender, maternal height, and maternal smoking during pregnancy. 
Table 4 Changes in diastolic blood pressure $(\mathrm{mm} \mathrm{Hg})$ associated with a $1 \mathrm{z}$ score increase in birth weight and weight for age $z$ scores at the mean ages of 20 months (1984), 42 months (1986), and 15 years (1997)

\begin{tabular}{|c|c|c|c|c|}
\hline \multirow[b]{2}{*}{ Model } & \multirow[b]{2}{*}{ Multiple linear regression equation } & \multicolumn{3}{|c|}{ Regression coefficient for diastolic blood pressure in 1997 (age 15 years) } \\
\hline & & All children & SGA & AGA \\
\hline 1 & Birthweight z score 1982 & $-0.17(-0.88$ to 0.51$)$ & $-1.15(-5.72$ to 3.43$)$ & $0.26(-0.60$ to 1.12$)$ \\
\hline 2 & $\begin{array}{l}\text { Birthweight } \mathrm{z} \text { score } 1982 \\
\text { Weight for age } \mathrm{z} \text { score } 1984\end{array}$ & $\begin{array}{l}-0.42 \text { (-1.18 to } 0.34) \\
0.53 \quad(-0.17 \text { to } 1.22)\end{array}$ & $\begin{array}{l}-1.32(-5.99 \text { to } 3.35) \\
0.50(-1.84 \text { to } 2.84)\end{array}$ & $\begin{array}{l}-0.01 \quad(-0.93 \text { to } 0.93) \\
0.52(-0.20 \text { to } 1.24)\end{array}$ \\
\hline 3 & $\begin{array}{l}\text { Birthweight } z \text { score } 1982 \\
\text { Weight for age z score } 1984 \\
\text { Weight for age z score } 1986\end{array}$ & $\begin{array}{l}-0.44(-1.20 \text { to } 0.32) \\
-0.03(-1.19 \text { to } 1.13) \\
0.69(-0.46 \text { to } 1.85)\end{array}$ & $\begin{array}{l}-1.33 \text { (-6.02 to } 3.37) \\
0.38 \text { (-3.58 to } 4.34) \\
0.15 \text { (-3.83 to } 4.12)\end{array}$ & $\begin{array}{l}-0.03(-0.96 \text { to } 0.90) \\
-0.08(-1.28 \text { to } 1.13) \\
0.75(-0.46 \text { to } 1.95)\end{array}$ \\
\hline 4 & $\begin{array}{l}\text { Birthweight z score } 1982 \\
\text { Weight for age z score } 1984 \\
\text { Weight for age z score } 1986 \\
\text { Weight for age z score } 1997\end{array}$ & $\begin{array}{l}-0.58(-1.32 \text { to } 0.17) \\
0.04(-1.09 \text { to } 1.18) \\
-0.73(-1.97 \text { to } 0.51) \\
2.36 \text { (1.53 to } 3.18)\end{array}$ & $\begin{array}{l}-1.40 \quad(-6.06 \text { to } 3.26) \\
0.43 \text { (-3.51 to } 4.37) \\
-1.19 \quad(-5.49 \text { to } 3.11) \\
2.18 \quad(-0.58 \text { to } 4.94)\end{array}$ & $\begin{array}{l}-0.17(-1.08 \text { to } 0.75) \\
0.05(-1.17 \text { to } 1.19) \\
-0.69(-1.98 \text { to } 0.60) \\
2.38(1.52 \text { to } 3.25)\end{array}$ \\
\hline $5^{*}$ & $\begin{array}{l}\text { Birthweight } z \text { score } 1982 \\
\text { Weight fo age } z \text { score } 1984 \\
\text { Weight for age } z \text { score } 1986 \\
\text { Weight for age } z \text { score } 1997\end{array}$ & $\begin{array}{l}-0.74(-1.49 \text { to } 0.02) \\
-0.13(-1.29 \text { to } 1.02) \\
-0.48 \text { (-1.73 to } 0.77) \\
2.36(1.53 \text { to } 3.19)\end{array}$ & $\begin{array}{l}-0.62(-5.64 \text { to } 4.41) \\
-0.01 \text { (-4.21 to } 4.20) \\
-0.32 \text { (-4.98 to } 4.34) \\
1.36 \text { (-1.59 to } 4.30)\end{array}$ & $\begin{array}{l}-0.25(-1.18 \text { to } 0.68) \\
-0.07(-1.28 \text { to } 1.14) \\
-0.55(-1.85 \text { to } 0.76) \\
2.44(1.57 \text { to } 3.31)\end{array}$ \\
\hline \multicolumn{2}{|c|}{ Number of children } & 749 & 101 & 648 \\
\hline
\end{tabular}

no significant interactions between birthweight $\mathrm{z}$ scores and the later $\mathrm{z}$ scores, and all $\mathrm{p}$ values for interactions were greater or equal to 0.37. After controlling for possible confounding variables (model 5), birth weight was still negatively associated with blood pressure, whereas weight for age z score at the age of 15 years continued to show a strong positive association with systolic blood pressure. Figure 1 shows the regression coefficients of systolic blood pressure on weight at the four different ages, and it is clear that the coefficients increase linearly with age. The negative coefficient at birth $(-1.23)$ compared with the positive coefficient at 15 years $(+4.38)$ shows that the coefficient increases at a rate of $(4.38-1.23) / 15=0.37 \mathrm{~mm} \mathrm{Hg} / \mathrm{z}$ score/year. This is effectively the slope of the line in figure 1 . This effect has been derived using the whole dataset, but it can be shown to apply at the individual level as well. For individuals who cross weight centiles upwards, each unit increase in z score per year is associated with a $0.37 \mathrm{~mm} \mathrm{Hg}$ rise in systolic blood pressure. The coefficients at all four ages lying on the same line, this means that the rate of centile crossing has the same impact on blood pressure throughout the age range. Centile crossing in infancy, or preschool, or before puberty, has exactly the same implication for systolic blood pressure in adolescence.

In contrast with systolic blood pressure, diastolic blood pressure was not associated with birth weight, not even when all four weights were included simultaneously in model 4 (table 4). For all children, and for those who were AGA, the positive association between weight in adolescence and blood pressure became stronger when previous weights were added to the model. Figure 2 shows the regression coefficients plotted against the mean age of the subjects at each follow up visit; in the first four years of life, the regression coefficients are similar, whereas there is an obvious trend in the weight coefficient between 42 months and 15 years.

\section{DISCUSSION}

In the first 20 months of life, rapid weight gain was more common among SGA than AGA infants. Birth weight was not associated with later blood pressure, whereas attained weights after birth were positively associated with systolic and-to a lesser extent—diastolic blood pressure. With birth weight and the later weights all included in the same regression model, the effect of birth weight on systolic blood pressure emerged

\section{Key points}

- Birth weight is unrelated to blood pressure in adolescence.

- Our study shows that early and late catch up are associated with increased systolic blood pressure in adolescence.

- Before promoting catch up growth, it is important to balance the pros and cons of rapid growth in infancy.

as significant and negative. This combination of a negative weight effect at birth and a positive weight effect later has been shown to correspond to a significant positive effect of weight gain on blood pressure. ${ }^{22}$ For systolic blood pressure, weight gain in infancy, pre-school, or before puberty, had exactly the same implication for later systolic blood pressure. For diastolic blood pressure the story is slightly different and centile crossing in the pre-school period does not have implications for later diastolic blood pressure, whereas late weight gain is related to increased diastolic blood pressure.

Some limitations may have affected the results of this study. It was not possible to locate $24.0 \%$ of the target population. However, the proportions of children with fast growth were similar among those who were located and those in the remainder of the original cohort; it is therefore unlikely that the above results have been affected by selection bias. Concerning the quality of the information, data collection was prospective and subjected to careful quality control; interviewers were carefully trained to administer the study questionnaire, and standardisation exercises were conducted to improve the precision and accuracy of the anthropometric and blood pressure measurements. On the other hand, blood pressure was measured twice in the same day, whereas it would be preferable to have three measurements. Any errors were probably independent of weight gain in early infancy, thus leading to an underestimation of the true effect. All but one of the previous studies on this issue failed to include weight at different ages in the regression model, ${ }^{11-17}$ and were therefore unable to pinpoint the period during which postnatal growth has a negative impact on adult health. In this study, it was possible to assess the contribution of fetal and postnatal growth on programming blood pressure at adolescence, as well as to evaluate when weight gain is critical in determining blood pressure. The results seem to contradict those of Eriksson et al, ${ }^{11}$ in Helsinki. They observed that an increase in body 
mass index from 3 years onward was associated with increased risk of coronary heart disease, but only among boys who were thin at birth. On the other hand, this study also reported that weight gain, or particularly gain in body mass index in early infancy, was protective of later coronary heart disease. This paper, however, has been criticised for failing to provide evidence to justify the statement and for suppressing the analysis that would show that weight gain in the first three years was unrelated to later coronary heart disease. ${ }^{23}$

As described in a separate analysis of the same Brazilian cohort ${ }^{24}$ catch up growth in early infancy has clear short-term benefits. SGA infants who presented substantial weight gain up to the age of 20 months had fewer hospital admissions and lower mortality between the ages of 20 and 42 months. Our findings, on the other hand, suggest that early-as well as late-catch up is associated with increased systolic blood pressure in adolescence. Those adolescents with higher blood pressure are in increased risk of have increased blood pressure in later ages. ${ }^{25}$ Our results show the need for more studies to balance the pros and cons of rapid growth in infancy, which has been referred to as "the catch up dilemma".

\section{Authors' affiliations}

B L Horta, School of Medicine and Psychology, Universidade Católica de Pelotas, Brazil

F C Barros, PAHO/WHO Latin-American Center for Perinatology and Human Development, Montevideo, Uruguay

F C Barros, C G Victora, Post-Graduate Programme in Epidemiology, Universidade Federal de Pelotas, Brazil

T J Cole, Centre for Paediatric Epidemiology and Public Health Biostatistics, Institute of Child Health, London, UK

Funding: BLH is supported by a Brazilian Research Council (CNPq) Scholarship.

Conflicts of interest: none.

\section{REFERENCES}

1 Tanner JM. Catch-up growth in man. Br Med Bull 1981;37:233-8

2 Karlberg J, Albertsson-Wikland K. Growth in full-term

small-for-gestational-age infants: from birth to final height. Pediatr Res 1995:38:733-9

3 Fitzhardinge PM, Steven EM. The small-for-date infant. I. Later growth patterns. Pediatrics 1972;49:671-81.

4 Kebede A, Larson C. The health consequences of intrauterine growth retardation in southwestern Ethiopia. Trop Doct 1994;24:64-9.
5 Barros FC, Huttly SRA, Victora CG, et al. Comparison of the causes and consequences of prematurity and intrauterine growth retardation: a longitudinal study in southern Brazil. Pediatrics 1992;90:238-44.

6 Tomkins A, Watson F. Malnutrition and infection: a review. Geneva: United Nations, 1989;29-40 (ACC/SCN State of the art series nutrition policy discussion paper; no 5).

7 Pelletier DL, Frongillo EA, Habicht JP. Epidemiologic evidence for a potentiating effect of malnutrition on child mortality. Am J Public Health 1993:83:1130-3

8 Klebanoff MA, Schulsinger C, Mednick BR, et al. Preterm and small-for-gestational age birth across generations. Am J Obstet Gynecol 1997;176:521-6.

9 Ramakrishnan U, Martorell R, Schroeder DG, et al. Role of intergenerational effects on linear growth. J Nutr 1999;1 29:544-9.

10 Barker DJP. Early growth and cardiovascular disease. Arch Dis Child 1999:80:305-7.

11 Eriksson JG, Forsén T, Tuomilehto J, et al. Early growth and coronary heart disease in later life: longitudinal study. BM 2001;322:949-53.

12 Forsén T, Eriksson JG, Tuomilehto J, et al. Growth in utero and during childhood among women who develop coronary heart disease: longitudinal study. BM 1999;319:1403-7.

13 Vanhala MJ, Vanhala PT, Keinänen-Kiukaanniemi SM, et al. Relative weight gain and obesity as a child predict metabolic syndrome as an adult. Int J Obes 1999;23:656-9.

14 Leon DA, Koupilova I, Lithell $\mathrm{HO}$, et al. Failure to realise growth potential in utero and adult obesity in relation to blood pressure in 50 year old Swedish men. BM 1996;312:401-6.

15 Fall CHD, Vijayakumar B, Barker DJP, et al. Weight in infancy and prevalence of coronary heart disease in adult life. BM 1995:310:17-20.

16 Hales CN, Barker DJP, Clark PMS, et al. Fetal and infant growth and impaired glucose tolerance at age 64. BMV 1991;303:1019-22.

17 Law CM, Barker DJP, Osmond C, et al. Early growth and abdominal fatness in adult life. J Epidemiol Community Health 1992;46:184-6.

18 Barros FC, Victora CG. Increased blood pressure in adolescents who were small for gestational age at birth: a cohort study in Brazil. Int J Epidemiol 1999;28:676-81.

19 Barros FC, Victora CG, Vaughan JP. The Pelotas birth cohort study, 1982-87. Strategies for following up 6000 children in a developing country. Paediatr Perinatal Epidemiol 1990;4:267-82.

20 Williams RL, Creasy RK, Cunningham GC, et al. Fetal growth and perinatal viability in California. Obstetr Gyneacol 1982;59:624-32.

21 Hamill PVV, Drizid TA, Johnson CL, et al. Physical growth: National Center for Health Statistics percentiles. Am J Clin Nutr 1979;32:607-29.

22 Lucas A, Fewtrell M, Cole TJ. Fetal origins of adult disease-the hypothesis revisited. BM 1999:319:245-9.

23 Cole TJ, Fewtrell M, Lucas A. Early growth and coronary heart disease in later life. BM 2001;323:572.

24 Victora CG, Barros FC, Horta BL, et al. Short-term benefits of catch-up growth for small-for-gestational-age infants. Int J Epidemiol 2001;30:1325-30.

25 Whincup P, Cook D, Papacosta O, et al. Birth weight and blood pressure: cross sectional and longitudinal relations in childhood. BM 1995;31 1:773-6. 